\title{
Cross-Cultural Collaborations
}

\author{
By Dr Louise Hamby
}

Louise Hamby is Guest Editor of this issue of craft + design enquiry. She is a Research Fellow in the Research School of Humanities and the Arts at The Australian National University. Her research is principally focussed on Arnhem Land material culture, historic and contemporary. Investigating the role of Indigenous people in the formation of collections from eastern Arnhem Land from the turn of the century until recent times is the topic of her current Australian Research Council project. In 2005 she was curator of the exhibition Twined Together: Kunmadj Njalehenjaleken and editor of the book of the same name. Her next exhibition from Gapuwiyak will open in September at Wagga Wagga Art Gallery.

\section{Editorial}

Cross-cultural exchanges in craft and design are the focus for the second issue of craft + design enquiry. Members of the Craft Australia Research Centre initiated the theme for this issue based on outcomes from the successful conference and workshop, Selling Yarns 2: Innovation for sustainability presented by The Australian National University, Craft Australia and the National Museum of Australia in March 2009. Indigenous textiles and fibre practice were at the heart of this event dedicated to all aspects of the economic expressions of fibre primarily by Aboriginal Australian artists. The call for papers for this issue was open to anyone who wished to contribute writing developed from any of the following themes:

- Tourism and museums as a driver for innovative cross cultural practice

- The role of design and manufacture in cross cultural engagement

- Innovation for social and cultural sustainability

- The impact of government policies on cultural sustainability

- Mentoring between communities

- The internet and the global market for Indigenous craft and design

I wish to thank all writers who submitted their work to craft + design enquiry and the peer-reviewers for the journal. We strive to achieve high quality research in the area of craft and design with contributors coming from diverse backgrounds: academics and/or practitioners from art, craft, design areas, material culture, anthropology, cultural studies and allied areas. The second issue's writers are academics and curators from the areas of art history, anthropology, material culture, craft and design. The artworks discussed in this issue are primarily of fibre. Various types of exchanges, from materials to techniques to collaborations, are covered. Kevin Murray's article asks difficult questions regarding collaborations 
between Australian designers and the makers of their products in Pakistan, India and Rwanda. The arena of Australian Aboriginal craft forms the major content of this issue with contributions by Christiane Keller, Sylvia Kleinert and Daphne Nash. Works from artists living in the south eastern part of Australia feature bringing to the forefront their contributions which have not always been as acknowledged as that of their northern counterparts. The types of objects discussed; fibre sculpture, shell work and clothing, are quite different but have in common a role in the maintenance and assertion of cultural identity for their makers. Perhaps this is where the biggest difference lies between the makers overseas and in the Australian Aboriginal work. The work produced overseas tends to retain more of the identity of the Australian designer rather than the Indigenous maker.

Christiane Keller points out in From Baskets to Bodies: Innovation within Aboriginal Fibre Practice that all the artists first learned to make functional items before venturing into sculptural works. This is most likely the case for most of the artists working in fibre who want their work seen as art. In order to bring to the forefront cultural identity many contemporary artists in the southeast go through a process of cultural renewal which often involves first learning about past techniques, materials and items made for

specific purposes regardless of the materials, shell or possum fur. Sylvia Kleinert in Clothing the postcolonial body: art, artifacts and action in south eastern Australia points to the effects of these revivals. 'Far from being a mere replication of the past, cultural revivals involve a complex process of recreation and transformation, proceeding by way of memory and history and narratives of identity and experience that carry political, moral and cultural force.'

Exchange of a cross-cultural nature in the broadest sense was the direction for the issue. The questions of what was exchanged, who was involved and the ultimate outcome of the exchange are ones I wish to interrogate. There are deliberate exchanges between different Australian Aboriginal people themselves. Within the Arnhem Land region of the Northern Territory, Rembarrnga and Kuninjku have exchanged techniques of twining pandanus in both the round and flat knotting of pandanus. In the Murray area of

Victoria, Ngarrindjeri women have taught others, and on the South Coast of New South Wales Cheryl Davison has taught other Aboriginal women shell techniques. There are the unknown exchanges that have taken place between the north and the south. The technique of coiling practiced by many Aboriginal women was taken to Arnhem Land by European missionaries and has become the major technique used by women now. In more recent times the Aboriginal women from different parts of the country have come together, as described by Keller with Two Countries, One Weave and in 2005 women from Gunbalanya worked with Victorian and South Australian women in workshops associated with Twined Together: Kunmadj Njalehnjaleken. Daphne Nash in her paper From 
shell work to shell art: Koori women creating knowledge and value on the South Coast of NSW records another exchange between missionaries and south coast women in regards to teaching shell work.

The other type of exchange noted by all authors is between non-indigenous and Indigenous people. Many of these have been in the areas of teaching techniques or styles of working to others. One of the most notable of these teachers/facilitators is Nalda Searles from Perth. She has worked with many Aboriginal people and others across the country teaching her own style of coiling and perhaps above all, confidence to express your own ideas with whatever materials you have to hand. Others like Thisbe Purich from Darwin, have worked to introduce basket-making skills to women from the desert with materials such as raffia and yarn. The mass manufactured materials, such as wool and synthetic yarns, are often used with natural ones like spinifex or reeds. Other artists like Lorraine Connelly-Northey take discarded materials to make powerful statements about their own cultural background. ConnellyNorthey makes references to both sides of her family heritage with works like An o'possum skin cloak.

The last type of exchange is one of collaboration or working together. The term collaboration has multiple meanings. For the purposes of our crosscultural interests I would like to define collaboration as a process in which two parties work together for a common goal. In the process there would be shared knowledge and experiences with equal benefit. Kevin Murray's case studies in his article Outsourcing the hand: An analysis of craft-design collaborations across the global divide provide the scope to understanding the range of collaborations and who benefits from them. The creative aspects of most of his studies were very much one-sided towards the Australian designer not the women making the product. If the common goal for most of these collaborations was an economic one, it is unclear whether or not both parties equally achieved the desired result. There are many other possible benefits including the revival of cultural skills, and improving the lifestyle of the people providing the labour. As Murray points out, 'What is needed now is a mechanism for authenticating the nature of participation in craft outsourcing.' And, I might add for collaborations across cultures, the nature of the creative aspects of the process.

I return to Selling Yarns 2 and its focus on the economic aspects of Aboriginal fibre in craft and design. This event was pivotal for collaboration between a group of Aboriginal women and Sasha Titchkosky from Koskela in Sydney. Titchkosky was seeking products made in Australia produced in collaboration with others. She was excited about fibre work from Arnhem Land and was seeking collaboration with makers. When Steve Hutchinson (former manager Elcho Island Arts and Craft) told her she should go to Selling Yarns: Australian Indigenous textiles and good business in the 21st century in Darwin in 2006, she responded with enthusiasm, 'Right, that is where I am going' (Titchkosky $2010 b)$. After thinking about product design and competition she visited Injalak Arts and Crafts to meet artists before she went to Selling Yarns 2. The reader is directed to Kevin Murrays article New Things: Koskela lights made in Elcho 
Island in Craft Australia's Library series (Murray 2010) for the rest of the story of the beginning of the collaboration with artists at Galiwin'ku and Mapuru and the exhibition resulting from this work, Yuta Badaya.

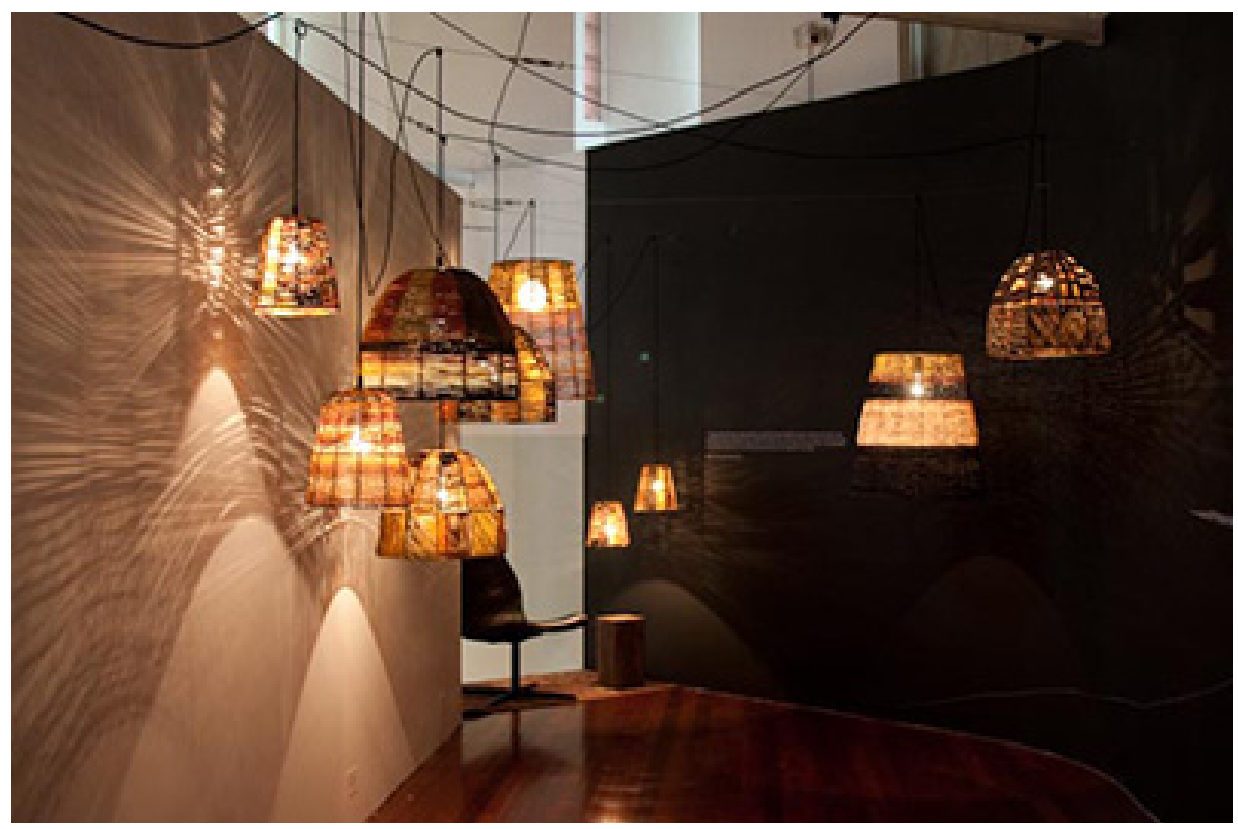

Plate 1: Yuta Badaya: In a New Light installation of lampshades. Object Gallery, Sydney. February 5, 2010.

Photograph: Louise Hamby.

In one sense this collaboration is not that different to the one undertaken by Martina Dempf and the artists from Rwanda described by Kevin Murray. A main difference being that in Rwanda, Dempf was trying to 'recover the lost tradition'. In Arnhem Land there was no need to recover any skills or materials; these have been well established for centuries. A concern of Titchkosky was the possibility that what was already accepted as an art form might be seen as a less acceptable commercial product. 'The idea of combining contemporary design with that traditional art form might be seen in some ways as devaluing the products or the pieces because we were taking them out of the gallery context.' This has been partially resolved in that within the range of products promoted and designed by Koskela these are seen as 'art pieces' (Titchkosky 2010a). Most people would have to agree with Titchkosky that after seeing the exhibition Yuta Badaya that 'As sculptural pieces they have two different lives, one life during the day and then another one at night-time where there is another dimension added to that particular form. (Titchkosky 2010b)' This has been the case partially because the women making these items have previous experience in making traditional cultural items in the same way that Keller points out in her article. 


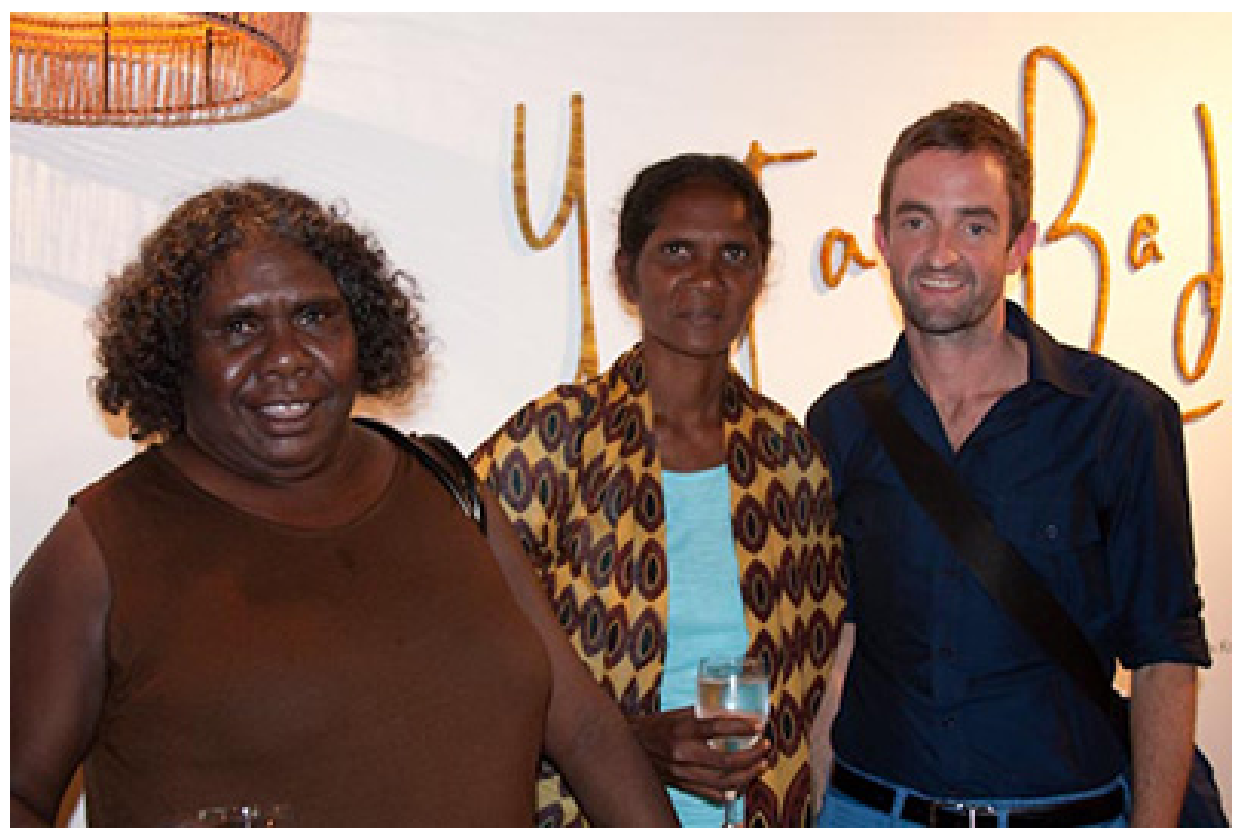

Plate 2: Roslyn Malngumba, Mavis Ganambarr and Dion Teasdale at the opening of Yuta Badaya. Object Gallery, Sydney. February 5, 2010.

Photograph: Louise Hamby.

Titchkosky realised that perhaps the collaboration did not start in the best way culturally with all the women, particularly Roslyn Malngumba.' It could have been a smoother path with her and the Mapuru weavers' due to the fact that she was not able to go to Mapuru to visit with the women there. The women did not really understand the project whereas Mavis Ganambarr had been involved earlier in the project. The collaboration continues past the exhibition. An economic goal was common for both parties. Titchkosky reiterates this but also points to the opportunities for newer audiences, not just for the lampshades but for their other work. 'It provides another legitimate avenue for her community to earn some income and participate in something that exposes their community and their art form to a whole other audience.'

The Arnhem Land-Koskela cross-cultural collaboration is an on-going one with different stages. The production of the exhibition at Object and two subsequent groups of lampshades are what Dion Teasdale, the Manager at Elcho Island Arts, refers to as the first stage of the process. The first group of work resulted in the creation of fourteen lampshades involving ten women. The artists from Galiwin'ku are Mavis Warrngilna Ganambarr, Margaret Gudumurrkuwuy, Rosemary Gutili, Mary Guyula and Kerry Malaray. The Arnhem Weavers Collective women from Maparu were Roslyn Malngumba, Linda Marathuwarr, Margaret Bambalara, Caroline Gulumindiwuy and Julienne Gitjpulu. This stage 
was characterised by women understanding how they could make their fibre styles fit within the standardised frames and accompanying safety regulations required to sell the lampshades.

From the beginning of the project Mavis Ganambarr has taken on a leadership role both with partner, Sasha Titchkosky, and with the women in Arnhem Land. She is the Artistic Liaison Officer for Elcho Island Arts and a talented artist in many fibre based media. Her role in the collaboration has been one in which she has been able to gain personal professional development skills in management and working with outsiders. She has overseen the making of the second grouping of eight lampshades, held meetings with the women as a group and sees each one individually to discuss their work. Teasdale reports that the women see the work as being two pieces, an artwork on its own and then a transformed piece when it is lit. Many of the women had not seen the works as lampshades with electric lights in place so the lighting of the second group was met by 'lots of squeals and magic (Teasdale 2010).'

The second stage of the project centres around a lampshade that Mavis Ganambarr brought to Sydney to discuss with Titchkosky and her partner Russell Koskela. This has subsequently been referred to as the frameless shade. This has been part of the great leap forward in the creative thinking of Ganambarr and the other women. It has lead to a period of research and development from both parties. The Aboriginal women have gone to the bush for alternative fibres to use as frames and Titchkosky has gone to other collaborators and manufactures to sort out structural, design and safety concerns (Teasdale 2010). This project has generated tremendous excitement which is spreading. Nicolas Rothwell noted in his recent article on Mavis Ganambarr. 'This is the context within which fresh forms of fibre art have spread so rapidly through Galiwinku: the art centre is full of work by women set on experiment (Rothwell 2010).' It has extended beyond Elcho. In March of this year the art staff from the fledging Gapuwiyak Culture and Arts Centre visited Elcho Island Arts to observe how everything was working there. When I visited Gapuwiyak in April of this year there were the beginnings of new lampshades hanging from the ceiling!

The Koskela-Arnhem Land collaboration is an exciting example of a crosscultural exchange involving design and manufacturing, mentoring between communities and an equitable outcome for all parties. The lampshade project has brought forward mentoring of less experienced artists by older ones in the same community and for those further afield in the same way as the explosion of fibre sculpture described by Keller, the shell work by Nash and the possum cloak revival by Kleinert. As more people become aware of projects like the ones discussed in this issue there will be more opportunities for individuals in design and manufacturing to form relationships with Indigenous artists. In order for these partnerships to function a relationship of trust and respect for the skills both parties bring has to be formed. This can lead to Indigenous artists gaining skills and abilities to produce and market their own work as we have seen with the Rwandan women's jewellery project described by Murray. It is an exciting time for artists working across cultures from an economic and creative aspect. 


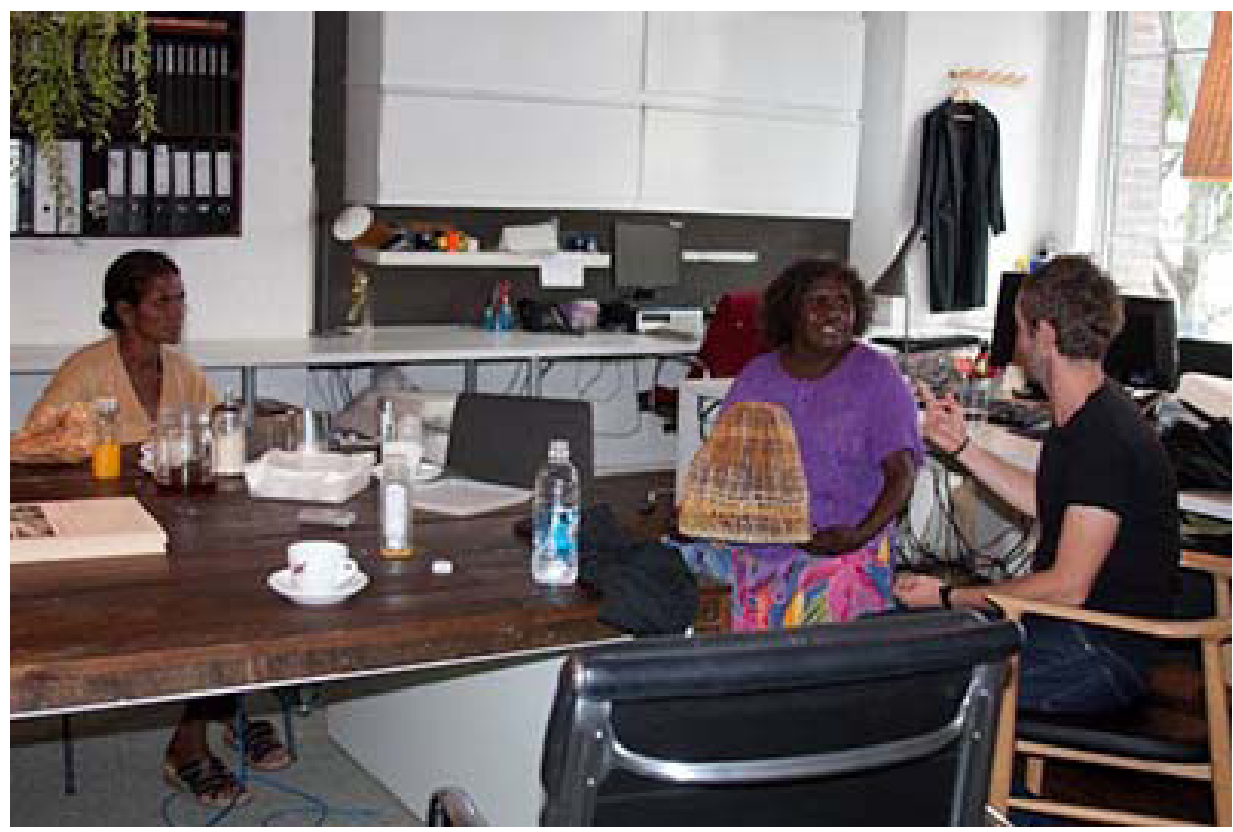

Plate 3: Mavis Ganambarr, Roslyn Malngumba holding the frameless lampshade and Dion Teasdale at the showroom of Koskela. Sydney. February 6, 2010.

Photograph: Louise Hamby.

\section{Bibliography}

Murray, K., 2010. New Things: Koskela made in Elcho Island. Craft Australia Library series. [Online] (Updated 15 Mar 2010) Available at: http://www. craftaustralia.org.au/library/review.php?id=yuta_badayala [Accessed 15 March 2010]. Rothwell, N., 2010. Experiments with tradition. The Australian, [Online] (Updated 23 April 2010) Available at: http://www.theaustralian.com. au/news/arts/experiments-with-tradition/story-e6frg8n6- 1225857137978 [30 April 2010].

Teasdale, D., 2010. Collaboration Update. [Discussion] (Personal communication, 3 May 2010)

Titchkosky, S., 2010 a. Showroom Discussion of Lampshades. [Discussion] (Personal communication, 5 February 2010)

Titchkosky, S., 2010 b . Class lecture at Object Gallery. [Lecture] (Object Gallery, Sydney, 5 February 2010) 